\title{
Article
}

\section{Preparation and characterization of bis- $[1,3,5]$ triazinyl diazenes and their utilization as flame retardants in polypropylene films}

Tirri, Teija, Aubert, Melanie, Pawelec, Weronika, Wilén, Carl-Eric, Pfaendner, Rudolf, Hoppe, Holger, Roth, Michael and Sinkkonen, Jari

Available at http://clok.uclan.ac.uk/13649/

Tirri, Teija, Aubert, Melanie, Pawelec, Weronika, Wilén, Carl-Eric, Pfaendner, Rudolf, Hoppe, Holger, Roth, Michael and Sinkkonen, Jari (2014) Preparation and characterization of bis-[1,3,5]triazinyl diazenes and their utilization as flame retardants in polypropylene films. Journal of Applied Polymer Science, 131 (12). ISSN 00218995

It is advisable to refer to the publisher's version if you intend to cite from the work. http://dx.doi.org/10.1002/app.40413

For more information about UCLan's research in this area go to http://www.uclan.ac.uk/researchgroups/ and search for <name of research Group>.

For information about Research generally at UCLan please go to http://www.uclan.ac.uk/research/

All outputs in CLoK are protected by Intellectual Property Rights law, including Copyright law. Copyright, IPR and Moral Rights for the works on this site are retained by the individual authors and/or other copyright owners. Terms and conditions for use of this material are defined in the policies page. 
Preparation and characterization of bis-[1,3,5] triazinyl diazenes and their utilization as flame retardants in polypropylene films

Tirri Tirri; Aubert Melanie; Pawelec Weronika; Wilén Carl-Eric; Pfaendner Rudolf; Hoppe Holger; Roth Michael; Sinkkonen Jari,

Journal of Applied Polymer Science 2014; 131, 12, 40413.

DOI: 10.1002/app.40413

\section{Preparation and characterization of bis-[1,3,5]triazinyl diazenes}

\section{and their utilization as flame retardants in polypropylene films}

T. Tirri ${ }^{1}$, M. Aubert ${ }^{1}$, W. Pawelec ${ }^{1}$, C.-E. Wilén ${ }^{1 *}$

R. Pfaendner ${ }^{2}$, H. Hoppe ${ }^{3}$, M. Roth ${ }^{4}$ and J. Sinkkonen ${ }^{5}$

\footnotetext{
${ }^{1}$ Laboratory of Polymer Technology, National Center of Excellence for Functionnal Materials (FUNMAT), Åbo Akademi University, Biskopsgatan 8, FIN-20500 Åbo, Finland

${ }^{2}$ Plastics Fraunhofer Institute for Structural Durability and System, Schloßgartenstr. 6, D-64289 Darmstadt

${ }^{3}$ BASF Schweiz AG, Klybeckstr. 141, CH-4057 Basel, Switzerland

${ }^{4}$ Product Development Industries Engineering Plastics Europe, BASF SE, E-KTE/IB F206, 67056 Ludwigshafen

${ }^{5}$ Department of Chemistry, University of Turku, FI-20014 Turku, Finland
}

*Corresponding author: Mobile: +358 50 4096406; e-mail: cwilen@abo.fi 


\begin{abstract}
A series of bis-[1,3,5]triazinyl diazenes and two metal complexes thereof were synthesized and tested as new flame retardants in polypropylene films. It was observed that electron withdrawing triazinyl ring substituents (i.e. $\mathrm{Cl}$ and phenyl moieties) improved the thermal stability of diazene compounds, whereas electron donating groups (i.e. methoxy, dimethylamino and ethylthio moieties) had a destabilizing effect. TGA, DTA/DSC, NMR and ATR-FTIR were used for the characterization. Quantum mechanical modeling (Gaussian 09) was also utilized to facilitate the interpretation of the NMR data. Bis-(4,6-dichloro-[1,3,5]triazin-2-yl)-diazene $\mathbf{1}$ and bis-(4,6-dimethoxy[1,3,5]triazin-2-yl)-diazene $\mathbf{2}$ were found to be effective flame retardants in polypropylene films and DIN4102-1 B2 classification was reached already at a loading of $0.5 \mathrm{wt} \%$. Interestingly, the copper complex of $\mathbf{2}$ showed even higher fire retardant activity than its precursor 2, whereas the corresponding zinc complex exhibited lower flame retardant efficacy than its precursor.
\end{abstract}

Keywords: Flame retardant, Polypropylene, Thermal properties, Bis-[1,3,5]triazinyl diazenes, Characterization 


\section{Introduction}

One of the first patents for flame retarded polypropylene (PP) was filed by MuellerTamm et $a l^{[1]}$ in 1964 . According to their invention polypropylene products are rendered highly flame resistant by melt blending of polypropylene with 1,2-dibromo-4( $\alpha, \beta$-dibromoethylcyclohexane) together with a metal oxide $\left(\mathrm{Sb}_{2} \mathrm{O}_{3}\right)$. Through the years a broad range of new halogenated flame retardants from inexpensive aliphatic, cyclic aliphatic, aromatic to aromatic-aliphatic structures in conjunction with antimony trioxide as a synergist have proved their high efficiency for fire-retarding a vast number of polymer substrates. The mechanism of brominated flame retardants is based on the formation of halides which inhibit the branching radical reactions that propagate a flame and thereby make the combustion of the polymeric material less efficient. The downside of this mechanism is that polymer substrates with brominated additives burn with a high smoke density and the products formed are acidic and corrosive. Furthermore, in recent years brominated flame retardants have been under scrutiny due to environmental concerns and their potential toxicity. Therefore, research efforts to find alternatives for halogenated flame retardants are well warranted.

Several halogen free solutions have been proposed, most of them being based on organic phosphorus, nitrogen or inorganic compounds either alone or in different combinations. ${ }^{[2-}$

${ }^{5]}$ Especially in the case of ATH, MDH or intumescent systems, high FR loadings are usually required leading to problems in processability and polymer property deterioration. The required amount of flame retardants can be strongly reduced by using appropriate synergists. One good example is polypropylene flame retarded with ATH alone, or in combination with $0.5 \mathrm{wt} \%$ of AZONOR compounds, whereupon the amount 
of ATH can be reduced from $60 \mathrm{wt} \%$ to $30 \mathrm{wt} \%$ and the combination still passes the UL 94-V2 standard. ${ }^{[6]}$

In particular, alternative nitrogen-based flame retardants that meet the requirements of sustainable production and products exhibit good overall prospects. Inspired by the already proven flame retardant efficacy of melamine compounds ${ }^{[7]}$ (melamine polyphosphate, melamine cyanurate, melamine borate) alkoxyamines (Flamestab NOR $116^{[8]}$, AZONOR $\left.^{[9-11]}\right)$, diazenes and related compounds ${ }^{[12-14]}$, triazenes ${ }^{[15]}$, inorganic azo compounds $^{[16]}$ (INAZO), as well as metal chelates ${ }^{[17]}$ and triazine polymers ${ }^{[18]}$ as charring agents, we started to explore the potential of different azo-linked bis triazines as flame retardants. We reasoned, that by the introduction of several known flame retardant building blocks such as azo moiety, triazinyl group or metal atoms into one molecule, a new class of flame retardant additives could be constructed.

Azo dyes, characterized by the presence of the chromophoric azo group $(-\mathrm{N}=\mathrm{N}-)$ between the aromatic nucleus, are well documented in the literature since they represent the largest and most versatile class of synthetic organic colorants used in the textile industry. ${ }^{[19]}$ Recently, these derivatives have also found numerous new applications ranging from optical waveguides ${ }^{[20]}$ and data storage devices ${ }^{[21]}$ to lightswitchable receptors ${ }^{[22]}$, and it is likely that new applications and discoveries will be made as the chemistries and structures are further refined. ${ }^{[23]}$

In contrast, very few examples of the synthesis or utilization of (N-phenyl-N'$[1,3,5]$ triazinyl)diazenes ${ }^{[24,25]}$, and even less of bis-[1,3,5]triazinyl diazenes ${ }^{[26,27]}$, can be found in the literature. The main reason is probably the difficulty of synthesizing such compounds by using the traditional diazotization-coupling route, which is employed in 
the synthesis of various azobenzene compounds. Nevertheless, plastic additives based on such structures are promising, because they combine two active flame retardant functions in one molecule. In contrast to azobenzenes ${ }^{[28]}$, bis-[1,3,5]triazinyl diazenes and their metabolites such as melamine (2,4,6-triamino-s-triazine) and mono or diamino$[1,3,5]$ triazine derivatives have high $\mathrm{LD}_{50}$ values, and these substances are not considered to be acutely toxic ${ }^{[29]}$, which makes them attractive compounds also from an environmental point of view.

Herein the efficacy of a series of substituted bis-[1,3,5]triazinyl diazenes as flame retardants in polypropylene films is reported. In addition, preliminary antiflame results for $\mathrm{Cu}$ - or Zn-complexes of bis(4,6-dimethoxy-[1,3,5]triazin-2-yl)diazene 2 are also presented.

\section{Experimental}

\subsection{General considerations}

All chemicals used were of reagent grade and purchased from Aldrich. ${ }^{1} \mathrm{H}$ and ${ }^{13} \mathrm{C}$ NMR spectra were recorded on a Bruker Avance $600\left({ }^{1} \mathrm{H} 600.1 \mathrm{MHz},{ }^{13} \mathrm{C} 150.9 \mathrm{MHz}\right)$ and ${ }^{1} \mathrm{H}-$

${ }^{15} \mathrm{~N}$ long-range $\mathrm{HMBC}$ on a Bruker Avance $500\left({ }^{1} \mathrm{H} 500.1 \mathrm{MHz},{ }^{15} \mathrm{~N} 50.7 \mathrm{MHz}\right)$ spectrometer. The spectral width for ${ }^{15} \mathrm{~N}$ domain was from -400 to $+100 \mathrm{ppm}$ in a scale where external nitromethane was referenced as $0.00 \mathrm{ppm}$. The one-bond and the multiplebond coupling constants were adjusted to 90 and $8 \mathrm{~Hz}$, respectively.

Thermogravimetric analyses (TGA/DTA) were performed using an SDT Q600 apparatus and differential scanning calorimeter (DSC) analyses were performed on Q1000 equipment both from TA Instruments. Measurements were done under $\mathrm{N}_{2}$ atmosphere at 
a heating rate of $10^{\circ} \mathrm{C} / \mathrm{min}$. Compounds $\mathbf{1}^{[30]}, 3^{[30]}, \mathbf{R}{ }^{[31]}$ and $\mathbf{R} 3^{[31]}$ were synthesized according to literature.

\subsection{Synthesis of bis-(4,6- dimethoxy -[1,3,5]triazin-2-yl)-diazene (2)}

\subsubsection{Preparation of N,N'-bis-(4,6- dimethoxy -[1,3,5]triazin-2-yl)-hydrazine.}

Hydrazine monohydrate $(1.7 \mathrm{~g}, 34.4 \mathrm{mmol})$ was added dropwise to a solution of 2chloro-4,6-dimethoxy -[1,3,5]triazine ${ }^{[32]}(12.1 \mathrm{~g}, 68.9 \mathrm{mmol})$ and potassium carbonate (9.5 g, $68.9 \mathrm{mmol})$ in isopropanol $(100 \mathrm{~mL})$. After stirring at $50{ }^{\circ} \mathrm{C}$ overnight, the product was filtered off, washed with water, recrystallized from acetonitrile and dried in oven to give a white powder. (5 g, $88 \%$ \%). ${ }^{1} \mathrm{H}-\mathrm{NMR}$ (DMSO): $\delta=9.78$ (s, 2H, NH), 3.88 (s, $6 \mathrm{H}$, $\mathrm{CH}_{3}$ ), 3.76 (s, $\left.6 \mathrm{H}, \mathrm{CH}_{3}\right) ;{ }^{13} \mathrm{C}-\mathrm{NMR}$ (DMSO): $\delta=172.8,172.3,170.1,54.9,54.7$ ATR-FTIR: 3250, 2957, 1546-1600, 1463, 1389, 1198, 1131, 1093, 811, $589 \mathrm{~cm}^{-1}$

\subsubsection{Preparation of Bis-(4,6- dimethoxy -[1,3,5]triazin-2-yl)-diazene.}

N,N'-bis-(4,6- dimethoxy -[1,3,5]triazin-2-yl)-hydrazine (7.4 g, $23.8 \mathrm{mmol})$ was slowly added to a stirred solution of N-Bromosuccinimide (20.4 g, $115 \mathrm{mmol}$ ) in acetonitrile (80 $\mathrm{mL}$ ). The suspension was stirred at room temperature for $2 \mathrm{~h}$. The product was filtered off, washed with acetonitrile $(2 \times 20 \mathrm{~mL})$ and cold water $(2 \times 20 \mathrm{~mL})$ and dried. Recrystalization from boiling acetonitrile yielded orange needles (5.7 g, 77 \%). ${ }^{1} \mathrm{H}-\mathrm{NMR}$ $\left(\mathrm{CDCl}_{3}\right): \delta=4.14\left(\mathrm{~s}, 12 \mathrm{H}, \mathrm{CH}_{3}\right) ;{ }^{13} \mathrm{C}-\mathrm{NMR}\left(\mathrm{CDCl}_{3}\right): \delta=176.5,174.0,56.3$

ATR-FTIR: 3025, 2953 (CH in CH3), 1511-1587 (C=N s-triazine), 1476, 1370, 1345 (C-O-CH3), 1238, 1106 (C-N=N, asym. str.), 1066 (C-N=N, sym. str), 921, 825 (striazine), $731,575 \mathrm{~cm}^{-1}$ 


\subsection{Synthesis of Bis-(4,6- diethylthio -[1,3,5]triazin-2-yl)-diazene (4)}

\subsubsection{Preparation of N,N’-bis-(4,6- diethylthio -[1,3,5]triazin-2-yl)-hydrazine}

Hydrazine monohydrate $(0.64 \mathrm{~g}, 12.75 \mathrm{mmol})$ was added dropwise to a suspension of 2chloro-4,6-bis(ethylthio)-[1,3,5]triazine ${ }^{[33]}(6.0 \mathrm{~g}, 25.5 \mathrm{mmol})$ and $\mathrm{NaOH}(1.9 \mathrm{~g}, 47.5$ mmol) in toluene $(50 \mathrm{~mL})$. The mixture was stirred at $80^{\circ} \mathrm{C}$ for $3 \mathrm{~h}$. After cooling the mixture to ambient temperature, it was extracted twice with water ( $25 \mathrm{~mL}$ ). The aqueous phase was acidified to $\mathrm{pH} 5$ with acetic acid. The precipitate obtained was filtered and dried under vacuum to yield a brownish solid $\left(0.4 \mathrm{~g}, 7\right.$ \%). ${ }^{1} \mathrm{H}-\mathrm{NMR}\left(\mathrm{CDCl}_{3}\right): \delta=8.40$ (s, 2H, NH), 3.13 (q, J= 7.5 Hz, 4H, CH 2$), 3.03$ (m, 4H, $\mathrm{CH}_{2}$ ), 1.37 (t, J= $7.5 \mathrm{~Hz}, 6 \mathrm{H}, \mathrm{CH}_{3}$ ), $1.21\left(\mathrm{~m}, 6 \mathrm{H}, \mathrm{CH}_{3}\right) ;{ }^{13} \mathrm{C}-\mathrm{NMR}\left(\mathrm{CDCl}_{3}\right): \delta=164.3,155.6,25.6,24.7,14.5,14.2$

\subsubsection{Preparation of bis-(4,6- diethylthio -[1,3,5]triazin-2-yl)-diazene}

Under argon atmosphere, a solution of bromine $(0.08 \mathrm{~g}, 1 \mathrm{mmol})$ in dry $\mathrm{CH}_{2} \mathrm{Cl}_{2}(0.5 \mathrm{~mL})$ was added to a suspension of N,N'-bis-(4,6- diethylthio -[1,3,5]triazin-2-yl)-hydrazine (0.4 g, $0.93 \mathrm{mmol})$ in $\mathrm{CH}_{2} \mathrm{Cl}_{2}(10 \mathrm{~mL})$, followed by a saturated aqueous solution of sodium bicarbonate ( $0.2 \mathrm{~g}, 2.38 \mathrm{mmol}$ ). The mixture was stirred for $30 \mathrm{~min}$ at ambient temperature. The organic phase was separated, washed twice with water (2x20 mL) and dried over $\mathrm{Na}_{2} \mathrm{SO}_{4}$. The solvent was evaporated under vacuum. Recrystallization from benzene/hexane yielded bis-(4,6- diethylthio -[1,3,5]triazin-2-yl)-diazene (0.23 g, 54 \%) as a yellowish solid. ${ }^{1} \mathrm{H}-\mathrm{NMR}\left(\mathrm{CDCl}_{3}\right): \delta=3.22\left(\mathrm{q}, J=7.2 \mathrm{~Hz}, 8 \mathrm{H}, \mathrm{CH}_{2}\right), 1.43(\mathrm{t}, J=7.2$ $\left.\mathrm{Hz}, 12 \mathrm{H}, \mathrm{CH}_{3}\right) ;{ }^{13} \mathrm{C}-\mathrm{NMR}\left(\mathrm{CDCl}_{3}\right): \delta=183.9,170.3,25.2,14.1$ 


\subsection{Synthesis of bis-(4,6-diphenyl-[1,3,5]triazin-2-yl)-diazene (5)}

\subsubsection{Preparation of N,N'-bis-(4,6-diphenyl-[1,3,5]triazin-2-yl)hydrazine}

A suspension of 2-chloro-4,6-diphenyl-[1,3,5]triazine ${ }^{[34]}$ (3.66g, $13.7 \mathrm{mmol}$ ) in $\mathrm{CH}_{3} \mathrm{CN}$ $(50 \mathrm{~mL})$ was added slowly to a mixture of 2-hydrazinyl-4,6-diphenyl-[1,3,5]triazine ${ }^{[35]}$ (3.00g, $11.4 \mathrm{mmol})$ and $\mathrm{NaHCO}_{3}(0.96 \mathrm{~g}, 11.4 \mathrm{mmol})$ cooled to $0{ }^{\circ} \mathrm{C}$. The suspension was refluxed for $2 \mathrm{~h}$ and cooled to room temperature. Water $(70 \mathrm{~mL})$ was added, and the precipitate was filtered and dried under vacuum to yield a white powder (5.30 g, $93.8 \%$ ). ${ }^{1} \mathrm{H}-\mathrm{NMR}$ (DMSO): $\delta=10.37$ (s, 2H, NH), 8.58 (d, $J=7.9 \mathrm{~Hz}, 4 \mathrm{H}$ ), 8.32 (d, $J=7.6 \mathrm{~Hz}$, 4H), 7.63 (m, 6H), 7.51 (t, $J=7.4 \mathrm{~Hz}, 2 \mathrm{H}), 7.42$ (t, $J=6.8 \mathrm{~Hz}, 4 \mathrm{H}) ;{ }^{13} \mathrm{C}-\mathrm{NMR}$ (DMSO): $\delta=170.9,170.6,167.9,135.7,135.6,132.5,132.4,128.8,128.6,128.3,128.1 ;{ }^{15} \mathrm{~N}-\mathrm{NMR}$ (DMSO): $\delta=-161.6,-269.6$

\subsubsection{Preparation of Bis-(4,6-diphenyl-[1,3,5]triazin-2-yl)-diazene}

An aqueous solution of $\mathrm{NaHCO}_{3}(1.80 \mathrm{~g}, 21.45 \mathrm{mmol})$ was added to a suspension of N,N'-bis-(4,6-diphenyl-[1,3,5]triazin-2-yl)hydrazine (5.30 g, $10.73 \mathrm{mmol})$ in $\mathrm{CH}_{2} \mathrm{Cl}_{2}$ (70 mL). A slow current of $\mathrm{Cl}_{2}$ was bubbled through the stirred suspension at ambient temperature until a red homogeneous organic phase was formed. The water phase was separated. The organic phase was washed twice with water $(100 \mathrm{~mL})$, dried over $\mathrm{Na}_{2} \mathrm{SO}_{4}$ and the solvent was evaporated to yield a reddish solid (4.7 g, $80 \%) .{ }^{1} \mathrm{H}-\mathrm{NMR}\left(\mathrm{CDCl}_{3}\right)$ : $\delta=8.72(\mathrm{~d}, J=7.3 \mathrm{~Hz}, 8 \mathrm{H}), 7.58(\mathrm{tt}, J=7.2 \mathrm{~Hz}, 1.1 \mathrm{~Hz}, 4 \mathrm{H}), 7.52(\mathrm{t}, J=7.9 \mathrm{~Hz}, 8 \mathrm{H}) ;{ }^{13} \mathrm{C}-$ $\operatorname{NMR}\left(\mathrm{CDCl}_{3}\right): \delta=174.5,174.2,135.0,133.5,129.6,128.8$ 


\subsection{Synthesis of bis-(4-phenyl-6-methoxy-[1,3,5]triazin-2-yl)-diazene (6)}

\subsubsection{Preparation of N,N'-bis-(4- phenyl-6-chloro -[1,3,5]triazin-2-yl)-hydrazine}

Hydrazine monohydrate $(1,0 \mathrm{~g}, 19.9 \mathrm{mmol})$ and $\mathrm{K}_{2} \mathrm{CO}_{3}(5,5 \mathrm{~g}, 39.8 \mathrm{mmol})$ was added to a solution of 4-phenyl-2,6-dichloro-[1,3,5]triazine $(9 \mathrm{~g}, 39.8 \mathrm{mmol})$ in $150 \mathrm{~mL}$ of $\mathrm{CH}_{2} \mathrm{Cl}_{2}$. The mixture was stirred for 5 hours at room temperature. The solvent was evaporated and the $\mathrm{pH}$ was adjusted to slightly acidic (5-6) by the addition of saturated solution of ammonium chloride. The precipitate was separated by filtration and dried under vacuum to give $6.1 \mathrm{~g}$ of the title compound (yield $70 \%$ ). ${ }^{1} \mathrm{H}-\mathrm{NMR}$ (DMSO): $\delta=$ 10.84 (s, 2H, NH), 8.30-8.10 (m, 4H), 7.71-7.46 (m, 6H); ${ }^{13} \mathrm{C}-\mathrm{NMR}$ (DMSO): $\delta=163.4$, 153.9, 133.6, 129.7, 129.3, 129.0, 128.9

\subsubsection{Preparation of N,N'-bis-(4- phenyl-6-methoxy -[1,3,5]triazin-2-yl)-hydrazine} $25 \mathrm{wt} \%$ solution of sodium methoxide in $\mathrm{MeOH}(12.6 \mathrm{~mL}, 74 \mathrm{mmol})$ was added to a solution of N,N'-bis-(4- phenyl-6-chloro -[1,3,5]triazin-2-yl)-hydrazine (6.5 g, 15.8 mmol) in $40 \mathrm{~mL}$ of $\mathrm{MeOH}$. The mixture was stirred at ambient temperature for $24 \mathrm{~h}$. The precipitate was separated by filtration and dried under vacuum to give $4.4 \mathrm{~g}$ of N,N'-bis(4-phenyl-6-methoxy-[1,3,5]triazin-2-yl)-hydrazine (yield: 69 \%) . ${ }^{1} \mathrm{H}-\mathrm{NMR}$ (DMSO): $\delta=9.65(\mathrm{~s}, 2 \mathrm{H}, \mathrm{NH}), 8.30(\mathrm{~m}, 4 \mathrm{H}), 7.48(\mathrm{~m}, 6 \mathrm{H}), 3.89\left(\mathrm{~s}, 2 \mathrm{H}, \mathrm{OCH}_{3}\right), 3.88(\mathrm{~s}, 1 \mathrm{H}$, $\mathrm{OCH}_{3}$ ), 3.84 (s, $1 \mathrm{H}, \mathrm{OCH}_{3}$ ), 3.82 (s, $\left.2 \mathrm{H}, \mathrm{OCH}_{3}\right) ;{ }^{13} \mathrm{C}-\mathrm{NMR}$ (DMSO): $\delta=172.7,172.7$, 172.3, 172.3, 172.0, 172.0, 171.5, 171.5, 169.5, 169.3, 169.2, 136.0, 136.0, 135.9, 135.9, 132.9, 132.8, 129.1, 129.1, 129.0, 128.7, 128.6, 128.5, 54.9, 54.9, 54.7, 54.7 


\subsubsection{Preparation of bis-(4-phenyl-6-methoxy-[1,3,5]triazin-2-yl)-diazene}

N-bromosuccinimide (8.32 $\mathrm{g}, 46.2 \mathrm{mmol})$ in $30 \mathrm{~mL}$ of acetonitrile was added to a solution of N,N'-bis-(4-phenyl-6-methoxy-[1,3,5]triazin-2-yl)-hydrazine (4.4 g, 10.9 mmol) in $120 \mathrm{~mL}$ acetonitrile. The mixture was stirred for $2 \mathrm{~h}$ at room temperature. The precipitate was filtered and washed with water to give $2.37 \mathrm{~g}$ of orange bis-(4-phenyl-6methoxy-[1,3,5]triazin-2-yl)-diazene (yield: $54 \%) .{ }^{1} \mathrm{H}-\mathrm{NMR}\left(\mathrm{CDCl}_{3}\right): \delta=8.50(\mathrm{~m}, 4 \mathrm{H})$, 7.76-7.59 (m, 6H), $4.19\left(\mathrm{~s}, 6 \mathrm{H}, \mathrm{OCH}_{3}\right) ;{ }^{13} \mathrm{C}-\mathrm{NMR}\left(\mathrm{CDCl}_{3}\right): \delta=175.6,175.2,172.9$, 134.6, 134.4, 129.6, 129.4, 56.5

\subsection{Synthesis of metal complexes (7) and (8)}

\subsubsection{Preparation of the copper complex (7)}

$\mathrm{Cu}(\mathrm{OAc})_{2}(3.23 \mathrm{~g}, 16 \mathrm{mmol})$ was dissolved in $100 \mathrm{~mL}$ of hot $\mathrm{H}_{2} \mathrm{O}-\mathrm{EtOH}(50 \mathrm{v} / \mathrm{v} \%)$ solution and 5 drops of acetic acid were added ${ }^{36}$. The prepared solution was then slowly poured into a solution of bis(4,6-dimethoxy-[1,3,5]triazin-2-yl)diazene (5 g, $16 \mathrm{mmol})$ dissolved in hot EtOH (300 mL). The mixture was refluxed under stirring for $3 \mathrm{~h}$ and slowly cooled down to room temperature. After $1 \mathrm{~h}$ refluxing, the color of the mixture changed to deep blue. Solvents were concentrated, and the precipitate was separated by centrifugation (7000 rpm, 10 min). The precipitate was washed with ethanol and $\mathrm{H}_{2} \mathrm{O}$ and separated after each step by centrifugation $(7000 \mathrm{rpm}, 10 \mathrm{~min})$. The product was dried overnight in vacuum oven over $\mathrm{P}_{2} \mathrm{O}_{5}$ to give $2.3 \mathrm{~g}$ of deep blue powder. ATR-FTIR $\left(\mathrm{cm}^{-}\right.$ 1): 3021, 2958, 1571, 1445, 1356, 1273, 1199, 1135, 1096, 940, 794, 613, 472. 


\subsubsection{Preparation of the zinc complex (8)}

Same procedure was used to prepare the zinc complex with $\left(\mathrm{Zn}(\mathrm{OAc})_{2}\right.$ (3.51 g, 16 mmol). The precipitate was separated by vacuum filtration and washed successively with $\mathrm{H}_{2} \mathrm{O}$, EtOH and diethyl ether to give $1.9 \mathrm{~g}$ of white powder. The precipitate was separated by vacuum filtration and washed successively with $\mathrm{H} 2 \mathrm{O}$, EtOH and diethyl ether to give $1.9 \mathrm{~g}$ of white powder.

ATR-FTIR $\left(\mathrm{cm}^{-1}\right):$ 2954, 1579, 1464, 1359, 1273, 1202, 1147, 1102, 945, 786, 612, 476.

\subsection{Evaluation of the flame retardancy: DIN 4102-1 /B2 flammability test}

The additives were melt compounded at a loading of 0.5 wt \% in a Brabender mixing chamber at $230{ }^{\circ} \mathrm{C}$ together with polypropylene. The resulting polymer compounds were pressed in a heated press at $230{ }^{\circ} \mathrm{C}$ into films of $200 \mu \mathrm{m}$ thickness and a size of $250 \times 100$ $\mathrm{mm}^{2}$. The films were mounted vertically inside a frame $\left(250 \times 90 \mathrm{~mm}^{2}\right)$ and subjected to an edge exposure from a gas flame at the angle of $45^{\circ}$. Noteworthy is, that instead of 20 mm flame length, which is described in the DIN4102-1 /B2 standard, $40 \mathrm{~mm}$ flame was used. We have earlier noticed that, for the particular azo candidates, $40 \mathrm{~mm}$ flame length allows for better differentiation of the flame retardant efficacy than using a flame length of $20 \mathrm{~mm}$. A filter paper was placed under the films to collect burning drips. The flame was applied for $15 \mathrm{~s}$. The specimen successfully passed the test, if the flame did not reach the $150 \mathrm{~mm}$ reference mark within the $20 \mathrm{~s}$ after the flame had been removed. Five, three or ten samples were ignited for each formulation. The damage length, burning time, weight loss and paper ignition were recorded. 


\section{Results and Discussion}

\subsection{Synthesis}

A series of bis-[1,3,5]triazinyl diazenes and two bis-[1,3,5]triazinyl diazene metal complexes, as shown in Scheme 1, were synthesized in order to evaluate if such derivatives possess flame retardant properties in polypropylene films. The structures of three reference compounds used in this study are also depicted in Scheme 1. 
<smiles>Clc1nc(Cl)nc(N=Nc2nc(Cl)nc(Cl)n2)n1</smiles>

1
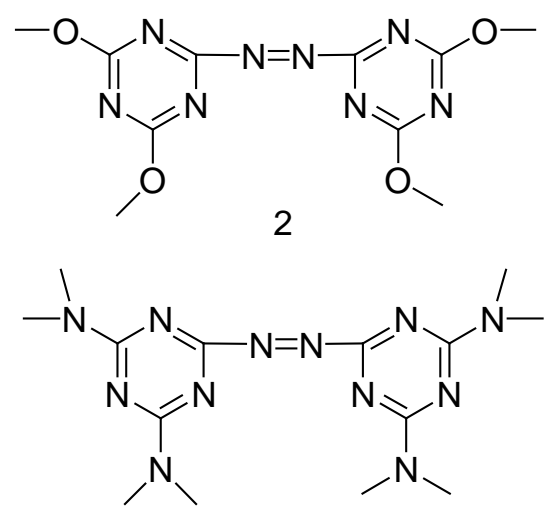

3<smiles>CCSc1nc(N=Nc2nc(SCC)nc(SCC)n2)nc(SCC)n1</smiles><smiles>c1ccc(-c2nc(N=Nc3nc(-c4ccccc4)nc(-c4ccccc4)n3)nc(-c3ccccc3)n2)cc1</smiles>

5<smiles>COc1nc(N=Nc2nc(OC)nc(-c3ccccc3)n2)nc(-c2ccccc2)n1</smiles>
6<smiles>COc1nc(N=Nc2nc(OC)nc(OC)n2)nc(OC)n1</smiles>

metal complex 7<smiles>[Z10]Oc1nc(N=Nc2nc(OC)nc(OC)n2)nc(OC)n1</smiles>
metal complex

8

Reference compounds<smiles>[R1][X]c1nc(Cl)nc(Cl)n1</smiles><smiles>[R20][C@@H]1Oc2ccccc2CN2CCN3Cc4ccccc4O[C@H]1C23</smiles><smiles></smiles>

Scheme 1. Synthesized bis-[1,3,5]triazinyl diazenes and reference compounds. 
All bis-[1,3,5]triazinyl diazenes were synthesized via oxidation of the corresponding N,N'-bis-triazinylhydrazine using halogens (i.e. $\mathrm{Br}_{2}, \mathrm{Cl}_{2}$ ) or N-bromosuccinimide as oxidizing agents. However, an universal and straightforward synthetic route to the various substituted N,N'-bis-triazinylhydrazines intermediate adducts could not be found. The original idea was to utilize the prepared precursor N,N'-bis-(4,6-dichloro$[1,3,5]$ triazin-2-yl)-hydrazine as a template for the preparation of various substituted bis$[1,3,5]$ triazinylhydrazines by a stepwise replacement of the chloride atoms by amines, alcohols or thiols, respectively. Unfortunately, this procedure was only successful in the case of the compound 3 (Scheme 2c.). Therefore the compounds 2 and $\mathbf{4}$ were instead prepared by first synthesizing the disubstituted monochloro-[1,3,5]triazine, followed by the reaction with hydrazine monohydrate at $80^{\circ} \mathrm{C}$ in an appropriate solvent (Scheme $2 \mathrm{~b}$ and 2d). Again, this new synthetic route failed to afford the phenyl-substituted derivatives 5 and 6. Finally, product 5 was obtained by first reacting 2-hydrazinyl-4,6-diphenyl[1,3,5]triazine with 2-chloro-4,6-diphenyl-[1,3,5]triazine in acetonitrile (Scheme 2 e), followed by oxidation of the hydrazine. Compound $\mathbf{6}$ was synthesized by reacting two equivalents of 4-phenyl-2,6-dichloro-[1,3,5]triazine with one equivalent of hydrazine monohydrate, followed by the substitution of the remaining chlorine atoms with sodium methoxide in methanol, and subsequent oxidation of the hydrazine (Scheme $2 \mathrm{f}$ ). 
a.<smiles>Clc1nc(Cl)nc(Cl)n1</smiles>

$\rightarrow$<smiles>Cc1nc(Cl)nc(NNc2nc(Cl)nc(Cl)n2)n1</smiles>

b.<smiles>COc1nc(Cl)nc(OC)n1</smiles>
1. $\mathrm{NH}_{2}-\mathrm{NH}_{2}, \mathrm{iPrOH}, \mathrm{K}_{2} \mathrm{CO}_{3}, 50^{\circ} \mathrm{C}$<smiles>COc1nc(NNc2nc(OC)nc(OC)n2)nc(OC)n1</smiles>

C.<smiles>Clc1nc(Cl)nc(NNc2nc(Cl)nc(Cl)n2)n1</smiles>
1. $\left(\mathrm{CH}_{3}\right)_{2} \mathrm{NH}(\mathrm{g})$, dioxane<smiles>CN(C)c1nc(NNc2nc(N(C)C)nc(N(C)C)n2)nc(N(C)C)n1</smiles>
2. $\left(\mathrm{CH}_{3}\right)_{2} \mathrm{NH}$ aq. sol., $80^{\circ} \mathrm{C}$

d.

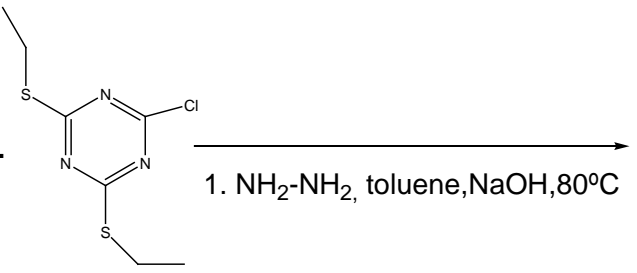<smiles>CCSc1nc(NNc2nc(SCC)nc(SCC)n2)nc(SCC)n1</smiles>

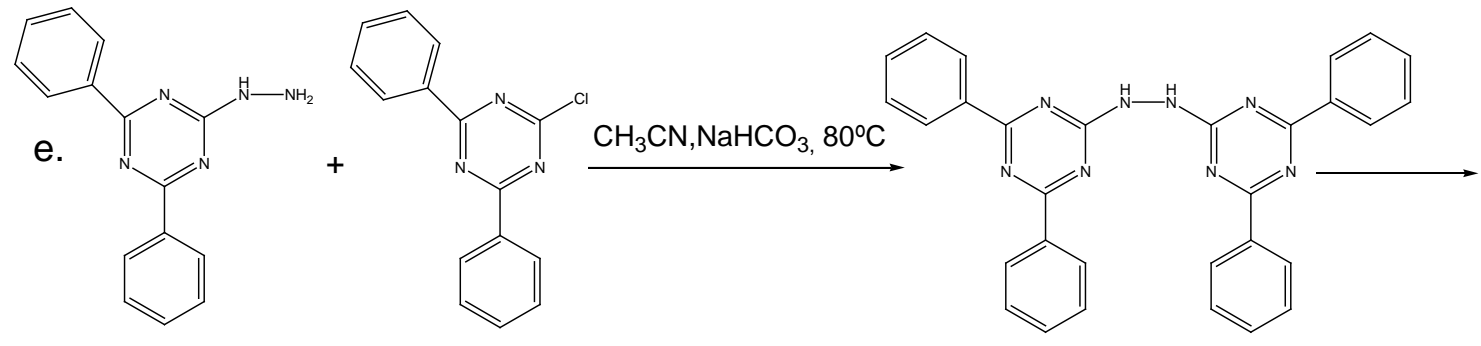<smiles>COc1nc(NNc2nc(Cl)nc(-c3ccccc3)n2)nc(-c2ccccc2)n1</smiles>

Scheme 2. Synthetic procedures for the preparation of substituted bis-[1,3,5]triazinyl diazenes. 


\subsection{NMR analysis and molecular modeling}

It was interesting to notice, that ${ }^{1} \mathrm{H}$ and ${ }^{13} \mathrm{C}$ NMR data of hydrazines were more complicated (multitude of peaks) than expected for such symmetrical molecules. Therefore, to further study the NMR behavior of hydrazine structures, molecular modeling was applied. Calculations were performed for the structurally simplest hydrazine 2. At room temperature, both ${ }^{1} \mathrm{H}$ and ${ }^{13} \mathrm{C}$ NMR spectra showed two magnetically non-equivalent methoxy groups. As the temperature was raised, a clear broadening of the signals was observed. At $80{ }^{\circ} \mathrm{C}$, only one methoxy signal was seen. These results indicate that some dynamic processes are ongoing within the structure. Tautomeric process was excluded, since the hydrazine ${ }^{1} \mathrm{H}$ NMR chemical shift and integration of $\mathrm{N}-\mathrm{H}$ protons does not change remarkably at room temperature or at $80{ }^{\circ} \mathrm{C}$. Therefore, the dynamic process was ascribed to rotameric equilibria.

To understand the process, compound 2 was modeled by hybrid DFT method B3LYP with $6-311+G(d, p)$ basis set by using Gaussian 09 software. ${ }^{[37]}$ The initial structure was first sketched by molecular mechanics (MM+) with HyperChem 7.5. The result of $\mathrm{MM}+$ calculation was planar structure, where NH-NH part was in trans orientation. Also another modified initial structure was sketched so that the hydrazine nitrogens had pyramidical sp3 hybridization. Both initial structures resulted in DFT optimization to planar trans geometry. Hydrazine bond had a stabilizing partial double bond character because of the $p-\pi$ conjugation between hydrazine bridge and triazinyl rings. In addition, planar geometry was strongly stabilized by intramolecular hydrogen bonds between NHprotons and N-atoms of triazinyl rings (Figure 1). 

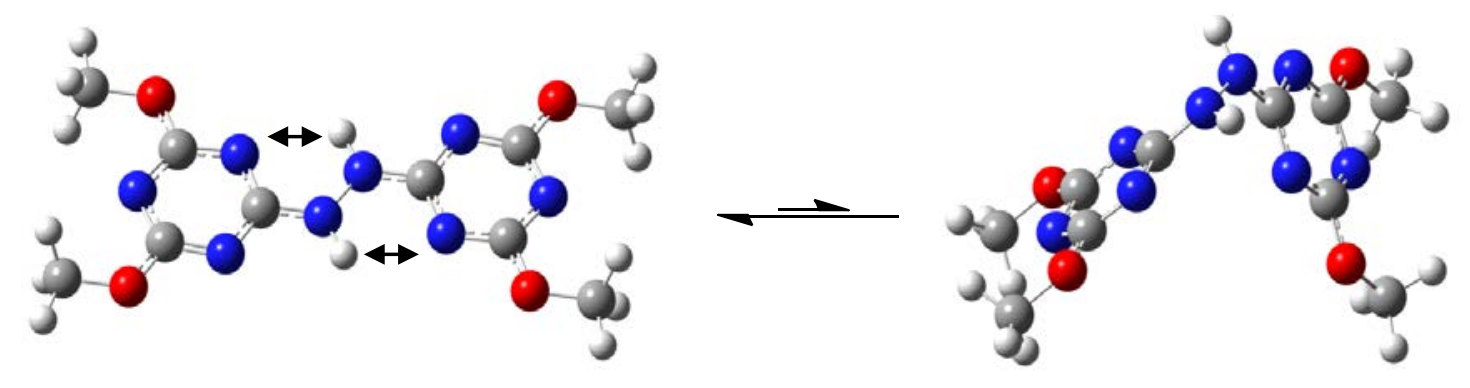

Figure 1. The B3LYP/6-3111G(d,p) optimized structures of the hydrazine precursor of 2. Intramolecular hydrogen bonds for planar structure are presented by arrows

If the planar trans geometry is assumed to be stable at room temperature, it explains the experimental NMR results, since the structure is symmetric so that two pairs of four methoxy groups are equivalent (Figure 1). When the temperature is increased, the rate of rotameric equilibrium may increase so that only one average signal is observed. Rotameric behavior was studied by doing a scanning calculation in which the torsion angle of hydrazine bridge C-N-N-C was varied from initial (planar trans) value of $180^{\circ}$ in $15^{\circ}$ steps to final value of $360^{\circ}$ (planar cis). The cis rotamer was found to be energetically much disfavored, because of the steric closeness of bulky triazinzyl moieties. Another minimum rotamer was found with torsion angle approximately $285^{\circ}$. This was fully optimized giving structure with $292^{\circ}$ angle and V-shape of structure (Figure 1). When the temperature was increased in NMR experiments, the energy barrier between these rotamers could be exceeded and only one average methoxy signal was seen in spectra. 
It seems reasonable to assume that rotameric equilibria can also explain the complex NMR data obtained also for the other similar hydrazine derivatives prepared in this study.

\subsection{Thermal analysis}

The thermal stabilities of the synthesized bis-[1,3,5]triazinyl diazenes were determined by TGA/DTA or DSC measurements. The decomposition temperatures (Table 1) are given at the point where the DTA/DSC exotherm reaches its maximum ( $\left.\mathrm{T}_{\text {dec, DTA }}\right)$ and at the point where $5 \%$ gravimetric loss is detected $\left(\mathrm{T}_{\mathrm{dec}}, 5 \%\right)$.

Table 1. Decomposition Temperatures and Char Yield of the Synthesized Bis$[1,3,5]$ triazinyl diazenes and Reference Compounds

\begin{tabular}{|l|l|l|l|l|l|l|l|l|l|l|l|}
\hline Compound & 1 & 2 & 3 & 4 & 5 & 6 & 7 & 8 & $\mathrm{R} 1$ & $\mathrm{R} 2$ & $\mathrm{R} 3$ \\
\hline $\mathrm{T}_{\text {dec.DTA }}\left({ }^{\circ} \mathrm{C}\right)^{\mathrm{a}}$ & $289 \mathrm{~b}$ & 242 & 239 & $206 \mathrm{~b}$ & 350 & 270 & 319 & 340 & $260^{[38]}$ & 344 & 423 \\
\hline $\mathrm{T}_{\text {dec,5\% }}\left({ }^{\circ} \mathrm{C}\right)^{\mathrm{c}}$ & 296 & 224 & 306 & - & 335 & 266 & 314 & 332 & - & 320 & 410 \\
\hline $\begin{array}{l}\text { Char residue } \\
(\%) \text { at } 700^{\circ} \mathrm{C}\end{array}$ & 0 & 9 & 13 & - & 18 & 16 & 20 & 43 & - & 35 & 58 \\
\hline
\end{tabular}
a) Peak of DTA exotherm
b) Peak of DSC exotherm
c) TGA weight loss $5 \%$, weight loss due to water (metal complexes) not taken into account

The results in Table 1 indicate, that the compound 4 exhibits too low thermal stability for the melt blending with polypropylene in an extruder operating at $230{ }^{\circ} \mathrm{C}$. Thus, this radical generator decomposes already during the polymer processing step, and can therefore no longer act as flame retardant in polypropylene films. All the other additives survived the melt blending step without significant thermal decomposition. The observed 
variations in the decomposition temperatures of the triazinyl azo additives appeared to be mostly dependent upon the electonic effects of their ring substituent. Thus, electronwithdrawing groups (i.e. $\mathrm{Cl}$ and phenyl moieties) improved the thermal stability of azo compounds, whereas electron-donating groups (i.e. methoxy, dimethylamino and ethylthio moieties) had the opposite effect. As could be anticipated, the compound 6, which contained both electron donating methoxy- and withdrawing phenyl-groups, decomposed at a temperature in between those of the compounds $\mathbf{2}$ and $\mathbf{5}$, that had either two methoxy or two phenyl pendant groups per ring, respectively. These results are in line with the previous study on the decomposition of tri-substituted single-ring triazines and azo- or hydrazo-linked bis-triazines with various substituents. ${ }^{[39]}$ In that study the usefulness of triazine compounds as novel energetic materials were examined, in particular of the triazido triazine based derivatives. A strong correlation was evident between the substituents on the triazine ring and the thermal stabilities measured by differential scanning calorimeter. In addition, it was found that the compounds exhibit similar thermal stabilities regardless of whether they were single-ring triazines or their linked analogs. The linkage between the triazine rings did not alter the decomposition of substituents nor trigger the decomposition of the triazine ring. In the case of azo-linked triazines, the breakage of the linkage, evidenced by the evolution of nitrogen, did not produce large quantities of carbonaceous gas according to gas chromatography and mass spectrometry (GC/MS) analyses. 


\subsection{Analysis of metal complexes}

A further method to optimize/regulate the thermal stability of the linked triazines is to form a metal coordinated azo complex. This technique has been successfully used in dyestuff industry in order to produce so-called mordant dyes with excellent fastness to light and washing ${ }^{[19]}$. Product 2 was reacted with $\mathrm{Cu}(\mathrm{OAc})_{2}$ or $\mathrm{Zn}(\mathrm{OAc})_{2}$ to yield a copper or a zinc complex, respectively (products 7 and 8). The copper complex 7 had a strong blue color, which is typical for copper complexes of diazenes and triazines due to metal to ligand charge transfer absorptions in the visible spectra. The exact structure of the complexes could not be determined by NMR or ESI-MS, because the complexes did not dissolve in any common solvents and are paramagnetic. Attempts to elucidate the crystal structure of 7 by X-ray powder diffraction were also unsuccessful. However, comparison of the ATR-FTIR data of 2 and 7 suggested, that the metal atom would bind both to the triazinyl ring and to the diazene nitrogens (Figure 2). 

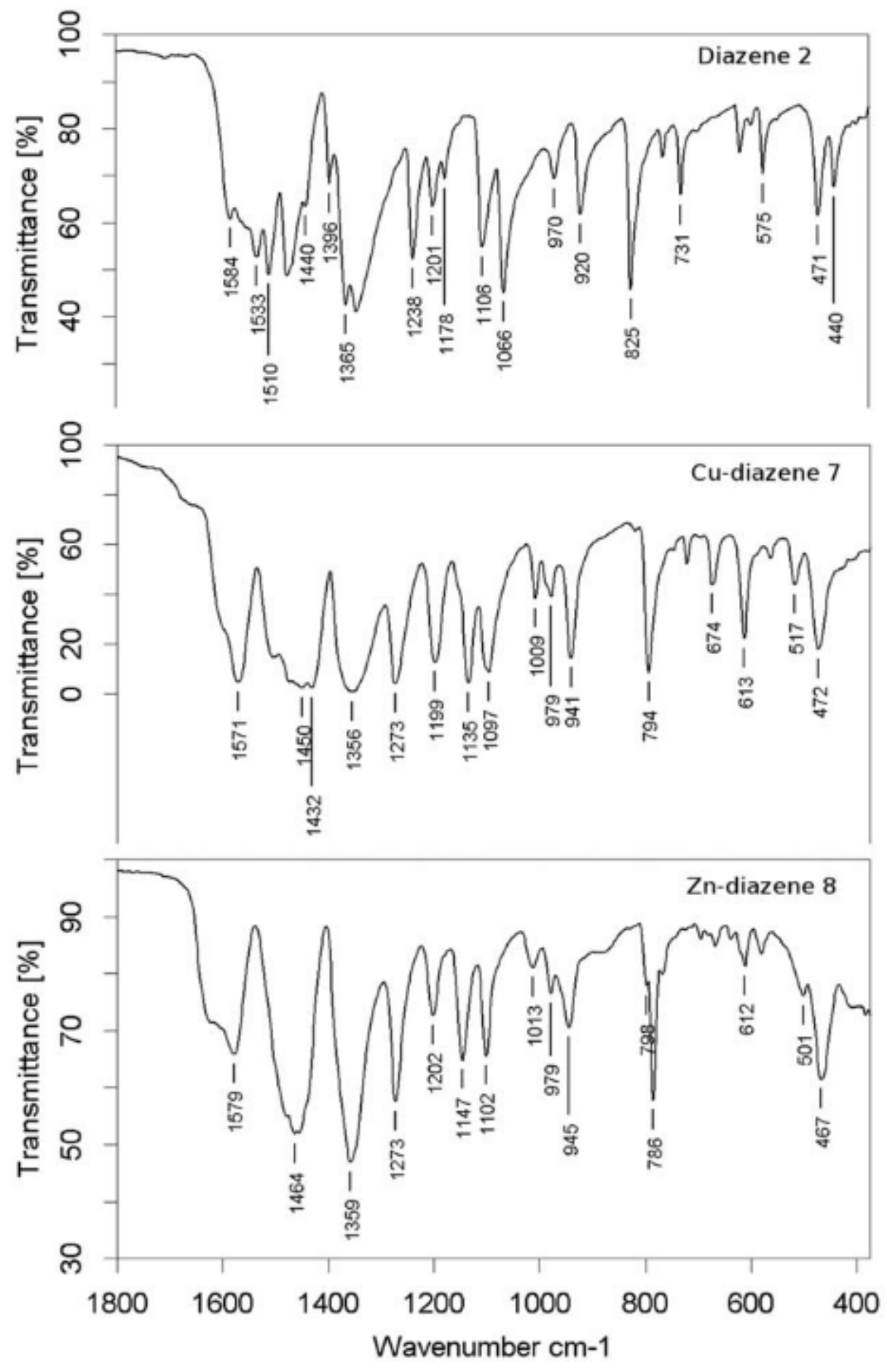

Figure 2. ATR-FTIR spectra of diazene 2 and its copper (7) and zinc (8) complexes. 
The absorption peak at $1238 \mathrm{~cm}^{-1}$ (tentatively assigned to $\mathrm{C}-\mathrm{N}=\mathrm{N}$ ) shifts up to $1273 \mathrm{~cm}^{-1}$, and the peak at $824 \mathrm{~cm}^{-1}$ assigned to s-triazine shifts down to $794 \mathrm{~cm}^{-1}$. In the characteristic absorption range of azo vibration $\left(1400-1500 \mathrm{~cm}^{-1}\right)^{[40,41]}$, several other bands corresponding to s-triazine semi-circle stretching, exo C-N contraction, -CH3 inphase bending and acetate $\mathrm{C}=\mathrm{O}$ stretching could also be detected. Therefore, it was difficult to assign the azo bond vibration frequency explicitly. However, two new strong signals were detected at 1450 and $1430 \mathrm{~cm}^{-1}\left(1476 \mathrm{~cm}^{-1}\right.$ for the compound 2), and the absorption band at $1540 \mathrm{~cm}^{-1}$ could not be seen anymore upon the coordination to the metal atom. ${ }^{[42-44]}$ As expected, TGA results indicate that the compounds 7 (Figure 2) and $\mathbf{8}$ are thermally more stable than the compound 2, but both metal complexes and $\mathbf{2}$ exhibit a similar three step decomposition pathway. In contrast, thermograms of the metal complexes, and more particularly of the chelate $\mathbf{8}$, showed that the rate of the second step was slower and the residual mass at $700{ }^{\circ} \mathrm{C}$ was higher in comparison to the precursor 2 . Owing to the fact that a new class of copper based flame retardants, such as $\mathrm{N}, \mathrm{N}^{\prime}$ bis(salicylidene)ethylenediamine copper(II) complex, has been successfully developed for thermoplastic polyurethanes ${ }^{[45]}$, we decided to include this copper complex and its zinc analogue as reference flame retardants in this study. 
Figure 3. Temperature difference (DTA, lower lines, Y offset 0.2) and weight loss (TGA, upper lines) curves for the diazene 2 and its copper- (7) and zinc- (8) complexes

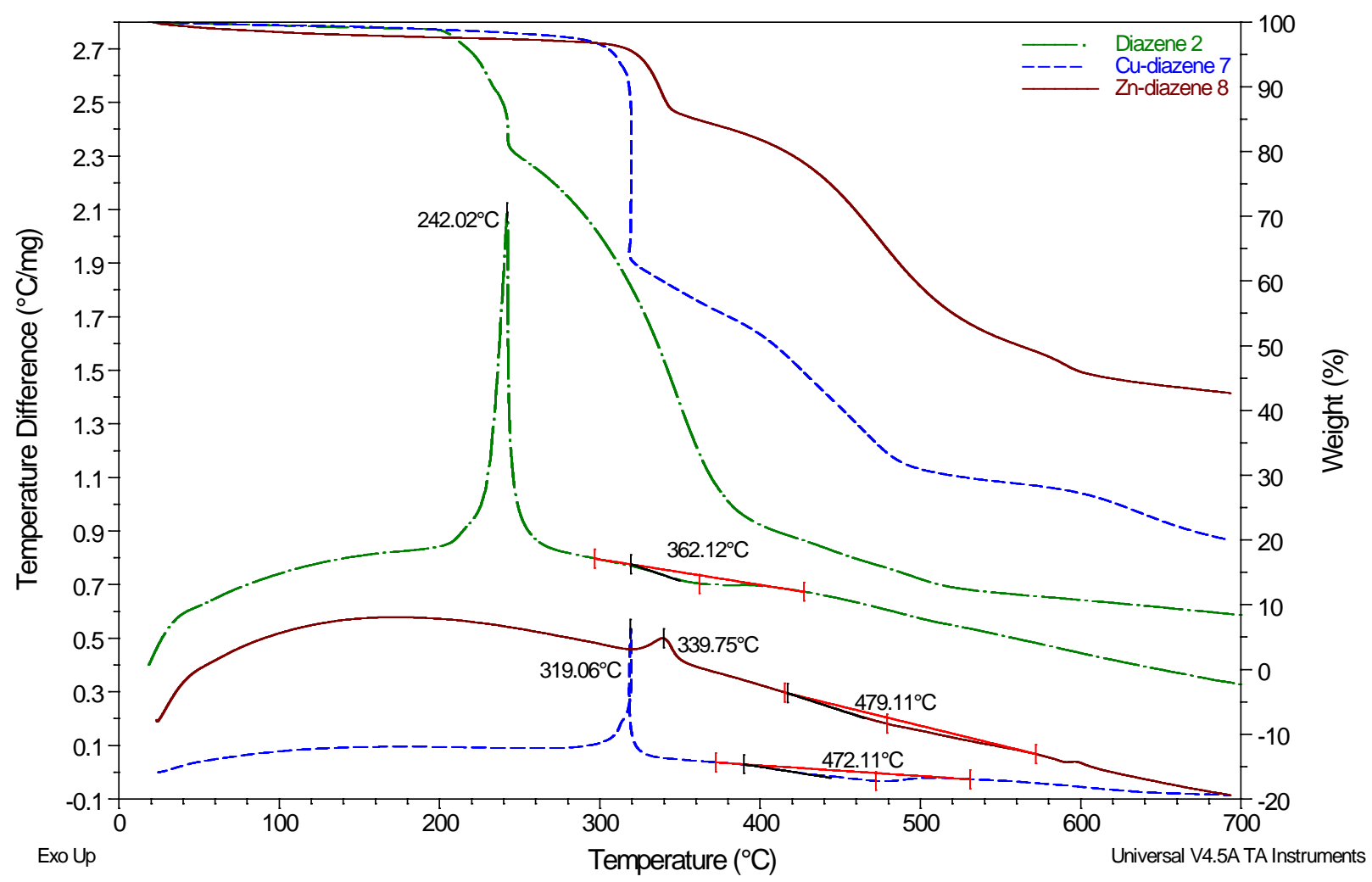

\subsection{Flame Retardant efficacy}

The fire retardant efficacy of the synthesized compounds was evaluated by performing a test according to norm DIN4102-1. The results are shown in Table 2. 
Table 2. The Flame Retardant Efficacy of Bis-[1'3’5] triazinyl azo metal complexes and reference compounds

\begin{tabular}{|c|c|c|c|c|}
\hline Compound & $\begin{array}{c}\text { Weight } \\
\text { loss (\%) }\end{array}$ & $\begin{array}{c}\text { Average damaged } \\
\text { length (mm) }\end{array}$ & $\begin{array}{c}\text { Burning time } \\
(\mathrm{s})\end{array}$ & DIN4102-B2 \\
\hline Reference PP & 100 & 190 & & N.C. $^{\text {b }}$ \\
\hline PP+1(0.5 wt.\%) & 3.3 & 79 & n.d. $^{\text {a }}$ & Pass $^{\text {c }}$ \\
\hline PP+2(0.5 wt.\%) & 8.8 & 96 & n.d. & Pass \\
\hline PP+3(0.5 wt.\%) & 40 & 163 & n.d. & N.C. \\
\hline PP+5(0.5 wt.\%) & n.d. & 152 & 39 & N.C. \\
\hline PP+6(0.5 wt.\%) & n.d. & 190 & 33.7 & N.C. \\
\hline PP+7(0.5 wt.\%) & n.d. & 80 & 16 & Pass \\
\hline PP+8(0.5 wt.\%) & n.d. & 155 & 28 & N.C. \\
\hline \multicolumn{7}{|c|}{ Reference flame retardant compounds } \\
\hline PP+R1(0.5 wt.\%) & 100 & 190 & 156 & N.C. \\
\hline PP+R2(2 wt.\%) & 45.6 & 117 & 32.7 & N.C. \\
\hline PP+R3(2 wt.\%) & 16.4 & 156.7 & Pass \\
\hline
\end{tabular}

\subsubsection{Substituted bis-[1,3,5]triazinyl diazenes}

The compound $\mathbf{4}$ was excluded from the test series, because it decomposed already during the polymer melt blending step. All other radical precursors were successfully melt compounded with polypropylene at a loading of $0.5 \mathrm{wt} \%$ and pressed into films of $200 \mu \mathrm{m}$ thickness. The highest flame retardant efficacy was recorded for the compound $\mathbf{1}$. In order to ascertain that the main flame retardant action of the compound $\mathbf{1}$ was not due to the liberation of chlorine atoms from the triazine ring, but rather due to the products generated from the thermolysis of the azo linkage, cyanuric chloride (R1) was used as a reference additive. Because the cyanuric chloride did not show any FR efficacy, the azo linkage is evidently necessary for obtaining good FR activity under these experimental conditions.

Of the remaining substituted bis-[1,3,5]triazinyl diazene compounds $\mathbf{2 , 3} \mathbf{3}$ and $\mathbf{6}$, only the compound 2 successfully reached the B2 classification in the DIN4102 standard test. The decay route of the compound $\mathbf{2}$ is known to be complex and it includes 
rearrangement products, such as hydrazine dimethoxy triazine and amino dimethoxy triazine by stepwise degradation, and decay species such as (6-amino-1,2,3,4-tetrahydro1,3-dimethyl-1,3,5-triazine-2,4-diol), carbon monoxide, methane, methanol and $\mathrm{CO}_{2}{ }^{[39]}$ The relatively high fraction of carbon-containing thermolysis products for triazine rings with pendant methoxy substituents is indicative of major triazine ring decomposition (triazines rings with no methoxy substituents undergo only minor ring decomposition). Due to the complex decomposition route of the compound 2, it is very difficult to pinpoint which of the species are the most essential ones for the flame retardant efficacy in polypropylene films. Therefore, this will be a subject for future studies.

As earlier mentioned, the screened compounds 3, 5 and $\mathbf{6}$ exhibited poor flame retardant activities under these experimental conditions irrespective of their promising decomposition temperatures. These results indicate that the thermal stability of the radical precursors is not the only priori for optimal performance, but other parameters, such as for instance the decomposition mechanism and the stability of the incipient radicals, also play an important role.

\subsubsection{Metal complexes and flame retardancy}

As anticipated, both metal complexes exhibited significantly improved thermal stabilities compared to the parent compound 2. However, the zinc complex 8 showed poor flame retardant activity, and it failed to pass the DIN4102-1 /B2 test, whereas the copper complex 7 passed it successfully with even shorter burning length compared to its precursor compound 2 . In this case, the results suggest that zinc has a deleterious effect 
on the FR activity whereas copper exhibits the opposite effect. It is clear, that besides improving the thermal stability of the azo linked triazine compound, the coordinated metal atom also alters the thermolysis pathway. In the case of copper, this is helpful for interrupting or suppressing the free radical combustion process. In fact, metal complexes have shown FR activity both in the vapor phase and in the condensed phase, depending upon the formulation and the application ${ }^{[46]}$. For instance, copper complexes (especially based on $\mathrm{Cu}(\mathrm{II})$ ) have been successfully used to flame retard $\mathrm{PVC}^{[47]}$ or polyurethane. ${ }^{[45]}$ As a consequence of this, copper (R2) and zinc (R3) metal complexes of $\mathrm{N}_{1} \mathrm{~N}^{\prime}$ bis(salicylidene)ethylenediamine were also prepared as reference metal complexes and their flame retardant properties were examined. The results are collected in Table 2. The reference metal complex $\mathbf{R} 2$ did not exhibit any significant flame retardant activity, whereas this time the zinc complex R3 passed the DIN4102-1 /B2 test at a loading of 2 wt\%. Nevertheless, the azo metal complexes exhibited much shorter damage length and burning time than $\mathbf{R} 3$.

These results indicate that, in order to reach a high level of flame retardancy, the choice of the metal in metal-organic compounds is of great importance. Further investigations are necessary to determine the mechanism of action in different metal-ligand combinations. Metal complexes of azo-linked triazines appear to offer new opportunities for the flame retardancy of polypropylene films. Further research is, however, needed before conclusions as to their usefulness as viable alternatives to halogenated flame retardants can be made. 


\section{Conclusions}

A series of bis-[1,3,5]triazinyl diazenes, and metal complexes thereof, have been successfully prepared and evaluated as novel flame retardants in polypropylene films. The obtained data shows, that the thermal stabilities of these compounds can be tuned by the selection of triazinyl ring substituents or by complexation with metal acetates. Among the triazine compounds examined, bis-(4,6-dichloro-[1,3,5]triazin-2-yl)-diazene $\mathbf{1}$, bis(4,6-dimethoxy-[1,3,5]triazin-2-yl)-diazene 2 and the copper complex of 2 exhibited the highest flame retardant efficacies, and all of them passed the DIN4102-1 B2 test criterion. These results suggest that bis-[1,3,5]triazinyl diazenes constitute a new and interesting family of flame retardants in polypropylene films. Besides alone, they could also be tested as synergists with other flame retardants or as char forming agents in intumescent systems.

\section{Acknowledgements}

The authors would like to thank BASF Schweiz AG, Center of Excellence of Functional Materials (FUNMAT), Finnish Academy of Science (KETJU programme), the Graduate Schools of Materials Research (GSMR) and Processing of Polymers and Polymer-based Multimaterials (POPROK) for financial support of this research. 


\section{References}

[1] Mueller-Tamm, H.; Seibt, H.; Zuern, L.; Scharf, E.; Mahling, D. FR 1360097, 1964.

[2] Laoutid, F.; Bonnaud, L.; Alexandre, M.; Lopez-Cuesta, J.-M.; Dubois, Ph. Mat. Sc. Eng. R., 2009, 63, 100.

[3] Morgan, A.; Gilman, J. Fire and Materials 2013, 37(4), 259.

[4] van der Veen, I. de Boer, J. Chemosphere 2012, 88(10), 1119. d) Schartel, B. Materials 2010, 3, 4710.

[5] Schartel, B. Materials 2010, 3, 4710.

[6] Aubert, M.; Tirri, T.; Wilén, C.-E.; Francois-Heude, A.; Pfaendner, R.; Hoppe, H.; Roth, M.; Pol. Deg. Stab. 2012, 97(8), 1438.

[7] Aelmans, N.; Kaprinidis, N.; Kierkels, R.; Steenbakkers, R.; Recent Advances in Flame Retardancy of Polymeric Materials, 2004, 15, 117.

[8] Horsey, D.; Andrews, S.; Davis, L.; Dyas, D.; Gray, R.; Gupta, A.; Hein, B.; Puglisi, J.; Ravichandran, R.; Shields, P. WO 9900450 A1, 1999.

[9] Roth, M.; Pfaendner, R.; Wilén, C.-E.; Aubert, M. WO 2008101845, 2008.

[10] Aubert, M.; Wilén, C.-E.; Pfaendner, R.; Kniesel, S.; Hoppe, H.; Roth, M. Polym. Deg. Stab. 2011, 96, 328.

[11] Wilen, C.-E.; Pfaendner, R. J. Appl. Polym.Sci. 2013, 129(3), 925.

[12] Nicolas, R.; Wilén, C.-E. WO 2005030852 A2, 2005.

[13] Nicolas, R.; Wilén, C.-E.; Roth, M.; Pfaendner, R.; King, R. E. I.; Macromol. Rap. Comm. 2006, 976.

[14] Aubert, M.; Nicolas, R.; Pawelec, W.; Wilén, C.-E.; Roth, M.; Pfaendner, R. Polym. Adv. Technol. 2011, 22, 1529. 
[15] Pawelec, W.; Aubert, M.; Pfaendner, R.; Hoppe, H.; Wilén, C.-E. Polym. Deg. Stab. 2012, 97, 948.

[16] Tirri, T.; Aubert, M.; Wilén, C.-E.; Pfaendner, R.; Hoppe, H.; Polym. Deg. Stab. 2012, 97, 375.

[17] Chantarasiri, N.; Chulamanee, C.; Mananunsap, T.; Muangsin, N. Polym. Deg. Stab. 2004, 86, 505.

[18] Li, B.; Xu, M. Polym. Deg. Stab. 2006, 91, 1380.

[19] Chudgar, R.; Oakes, J. Kirk-Othmer Encyclopedia of Chemical Technology (5th Edition), John Wiley \& Sons, Hoboken, 2005, 9, 349.

[20] Chigrinov, V.; Kwok, H.; Takada, H.; Takatsu, H. Liq. Cryst. Tod. 2005, 14, 1.

[21] Zilker, S.; Bieringer, T.; Haarer, D.; Stein, R.; van Egmond, J.; Kostromine, S. Adv Mater. 1998, 11, 855.

[22] Dugave, C.; Demange, L. Chem. Rev. 2003, 7, 2475.

[23] Zhao, Y.; Ikeda, T. Smart light-responsive materials: Azobenzene-containing polymers and liquid crystals, John Wiley \& Sons, Hoboken, 2009.

[24] Inoue, Y.; Keumi, T.; Kitajima, H. Chemistry Express 1988, 7, 423.

[25] Inoue, Y.; Kamo, Y.; Togo, M.; Hsu, Y. C.; Keumi, T.; Kitajima, H. Chem. Lett. 1981, 1733.

[26] Mikhailov, Y.; Chapyshev, S.; Nedel'ko, V. Russian Chemical Bulletin 2009, 10, 2097.

[27] Huynh, M.; Hiskey, M.; Chavez, D.; Naud, D.; Gilardi, R. J. Am. Chem. Soc. 2005, $36,12537$. 
[28] Milman, H.; Weisburger, E. Handbook of Carcinogen Testing (2 ${ }^{\text {nd }}$ Edition), Noyes, Park Ridge, 1994.

[29] Skinner, C.; Thomas, J.; Osterloh, J. J. Med. Tox. 2010, 1, 50.

[30] Loew, P.; Weis, C. J. Het. Chem. 1976, 4, 829.

[31] Ribeiro da Silva, M.D.; Gonçalves, J.; Silva, A.; Oliveira, P.; Schröder, B.; Ribeiro da Silva, M.A. J. Mol. Catal. A: Chem. 2004, 224, 207.

[32] Duliban, J. Macromol. Mat. Eng. 2006, 291, 137.

[33] Koopman, H.; Daams, J.; Rec. Trav. Chim. Pays-Bas et Belgique 1960, 83.

[34] Zhong, H.; Xu, E.; Zeng, D.; Du, J.; Sun, J.; Ren, S.; Jiang, B.; Fang, Q. Org. Lett. 2008, 10, 709.

[35] Yamanaka, H.; Ohba, S.; Konno, S. Heterocycles, 1987, 11, 2853.

[36] Kandil, S; El-Hefnawy, G.; Baker, E. Thermochimica Acta 2004, 2, 105.

[37] Gaussian 09, Revision A.02, Frisch, M. J.; Trucks, G. W.; Schlegel, H. B.; Scuseria, G. E.; Robb, M. A.; Cheeseman, J. R.; Scalmani, G.; Barone, V.; Mennucci, B.; Petersson, G. A.; Nakatsuji, H.; Caricato, M.; Li, X.; Hratchian, H. P.; Izmaylov, A. F.; Bloino, J.; Zheng, G.; Sonnenberg, J. L.; Hada, M.; Ehara, M.; Toyota, K.; Fukuda, R.; Hasegawa, J.; Ishida, M.; Nakajima, T.; Honda, Y.; Kitao, O.; Nakai, H.; Vreven, T.; Montgomery, J. A.; Jr., Peralta, J. E.; Ogliaro, F.; Bearpark, M.; Heyd, J. J.; Brothers, E.; Kudin, K. N.; Staroverov, V. N.; Kobayashi, R.; Normand, J.; Raghavachari, K.; Rendell, A.; Burant, J. C.; Iyengar, S. S.; Tomasi, J.; Cossi, M.; Rega, N.; Millam, J. M.; Klene, M.; Knox, J. E.; Cross, J. B.; Bakken, V.; Adamo, C.; Jaramillo, J.; Gomperts, R.; Stratmann, R. E.; Yazyev, O.; Austin, A. J.; Cammi, R.; Pomelli, C.; Ochterski, J. W.; Martin, R. L.; Morokuma, K.; Zakrzewski, V. G.; Voth, G. A.; Salvador, P.; Dannenberg, 
J. J.; Dapprich, S.; Daniels, A. D.; Farkas, Ö.; Foresman, J. B.; Ortiz, J. V.; Cioslowski, J.; Fox, D. J. Gaussian, Inc., Wallingford CT, 2009.

[38] Singh, M. Synthetic Communications, 2008, 38, 2898.

[39] Oxley, J.; Smith, J.; Moran, J. J. Energ. Mat. 2009, 27, 63.

[40] Larkin, P.; Makowski, M.; Colthup, N.; Flood, L. Vibrational Spectroscopy 1998, $17,53$.

[41] Lin, Z.; Han, D.; Li, S. J. Therm. Anal. Calorim. 2012, 107, 471.

[42] Petredis, D.; Burke, A.; Balch, A.; J. Am. Chem. Soc. 1970, 92 (2), 428.

[43] Chen, Z.; Wu, Y.; Gu, D.; Gan, F. Dyes and Pigments 2008, 76, 624.

[44] Huang, F.; Wu, Y.; Gu, D.; Gan, F. Mat. Lett. 2004, 58, 2461.

[45] Fontaine, G.; Bourbigot, S.; Duquesne, S. 253th ACS meeting, New Orleans, LA, United States, 2008, PMSE-430.

[46] Morgan, A. ACS Symposium Series, Fire and Polymers V, 2009, 312.

[47] Starnes, W.; Pike, R.; Cole, J.; Doyal, A.; Kimlin, E.; Lee, J.; Murray, P.; Quinlan, R.; Zhang, J. Polym. Degrad. Stab. 2003, 82, 15. 
